\title{
Pitwall Stability Analysis-Case Studies*
}

\author{
M. Affam and K. E. Allen
}

Affam, M. and Allen, K. E., (2009), “Pitwall Stability Analysis-Case Studies”, Ghana Mining Journal, Vol. 11, pp. 31 - 36.

\begin{abstract}
The importance of pitwall stability in design and economy of open pits has been a subject of considerable research in rock mechanics for some time now. Imperceptible slow mass movement has been a secret agent in inducing major pitwall failure. The problem is location specific and is associated with stress development, shear strength, discontinuity orientations and groundwater regimes. This paper therefore sets out to present pitwwall stability analysis in some selected pits within the Birimian environment in Ghana. Several attitude measurements were taken particularly on the footwall and along the slope face of the oxide, transition and fresh (sulphide) rock materials from some selected pits. The geologic data was subjected to the Romana's Slope Mass Rating (SMR) analytical procedure and the pitwalls monitored through installed prisms.

The oxide/ transition zones gave an SMR quantitative value of 43.1 in the footwall and 44 within the hangingwall, indicating a partial stability at $50^{\circ}$. The fresh rock (sulphide) gave a value of 64 in the footwall showing stability at $55^{\circ}$. As usual, the fresh rock was less problematic as indicated by the SMR assessment compared to the oxide and the transition materials. Creep movement was observed to predominate, being nearly $250 \mathrm{~mm}$ /day within the oxidised zone but lesser in the transition and fresh rocks. Induced pitwall failure pattern within the Birimian was more of composite failure (ie.,planar and toppling) capable of destabilising several pits if unchecked.
\end{abstract}

\section{Introduction}

It is observed that in all slopes, there exists an inherent tendency to degrade to a more stable form, ultimately towards horizontal. Instability is seen as the tendency to move and failure as an actual mass movement (Whitlow, 1995). The detachment and movement of the earth material occur if the stress imposed on the material is greater than the shear strength capable of holding it in place.

Mass movement is usually slow and largely imperceptible to the naked eye. Creep is perhaps, the slowest of all the types of mass movements, triggering slope failures and precipitated by variation in conditions such as changes in water content, stress development, loading and surface instability (e.g. removal of vegetation). In the analysis of cut and built slopes, it is realized that failure may also be associated with geological structure of the host rocks itself. These changes may be observed during or immediately after excavation, or may be imposed suddenly at any time (Whitlow, 1995). The slope of the excavation determines the amount of stress magnitude occurring within the material. Tension cracks and hummocky grounds are some visible signs of relative movement.

The occurrence of visible micro cracks, jointing and penetrative tension cracks in the Main Pit (MP) of Central African Mine Ltd., Bibiani and

\footnotetext{
* Manuscript received March 30, 2009

Revised version accepted December 3, 2009
}

the Plant North Pit (PNP) of Golden Star Resources, Bogoso/Prestea Mine, Prestea, both within the Birimian environ, required stability assessment of the slope walls. For instance, MP totally failed before the ultimate pit bottom was reached. (Figs.1 and 2). PNP which was expected to reach $4924 \mathrm{~m}$ reduced level (RL) began showing signs of possible failure at an initial stage of $5014 \mathrm{~m}$ (RL). The observed structural discontinuities are early warning signs capable of triggering eventual macro failure as creep effects are more conducive in environment of numerous tension cracks.

Due to the fact that any unprecedented failure of the pitwalls could result in economic penalties such as loss of property and life, the need to look for remedial measures to maintain the pitwall is important. Workable stability analysis would not only provide measures to save the pit from eventual collapse but also save the company from investment loss and loss of livelihood for the numerous employees. It is against this background that this paper sets out to investigate areas of potential failure induced by movement within the pit walls by employing techniques that examine unstable benches or walls and monitor their displacement in order to analysis the stability of walls for immediate redress. The study is also intended to develop remedial measures to ensure creep-free pitwalls. 


\subsection{Slope Stability in Open Pit Mining}

In open pit mining, mineral deposit are mined from the ground surface downward. Consequently, pit slopes are formed as the ore is extracted. It is sometimes difficult to maintain stable vertical slopes or pit walls of substantial height even in very hard and competent rocks. This is because the slope of the surface determines the amount of stress that occurs on the material and therefore the economics of the pit operations are to a large extent linked to the slope geometry (Ross-Brown, 1972). The pit walls must be inclined at some angle to prevent failure of the rock mass. This angle is governed by the geo-mechanical conditions at a specific mine and represent an upper bound to the overall slope angle. Any miscalculation could trigger instability and eventual failure sometime later (Fig.1 and Fig.2). The actual slope angles used in the mine depend upon:

- Presence of ramps or haul roads

- Possible blast damage

- Ore grade and economic constraints

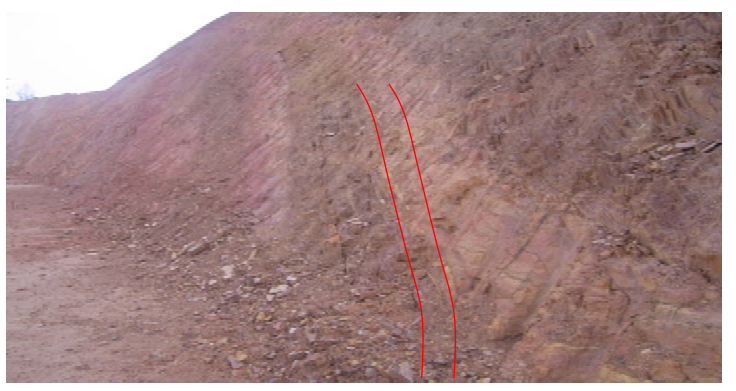

Fig. 1 Unstable Pitwall showing Tension Cracks (in red) at Initial Excavation Stage

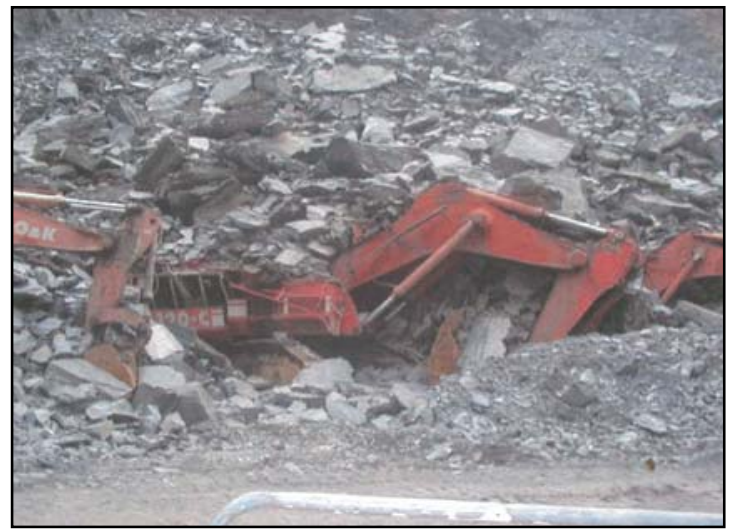

Fig. 2 Burried Equipment Due to Total Pitwall Failure in Bibiani Main Pit (MP)

Water also destabilises the cut slopes by creating pressure in the pore spaces of the material medium. The infiltrated water into the slope face saturates the weaker materials at depth, reduces the frictional bond between the particles and causes beds to slip past one another. The weight of the overlying water therefore creates excess pressure that drives the particle apart.

\section{Geological Setting}

\subsection{Brief Local Geology}

The Birimian supergroup forms part of the Man Shield in the southern segment of the West Africa Craton (Leube et al, 1990). Within the study area, the Birimian structural trend is referred to as the central structural corridor or central fault zone, striking NE-SW.

The central structural corridor separates the Birimian structural domain in the west from the Tarkwaian structural domain in the east with both suites hosting an anastomosing network of faults and imbricate faults, volcaniclastic rocks deposited in shallow marine basins separated by a subparallel series of north-east trending volcanic belts (Taylor et al; 1988). The transition between volcanic belts and sedimentary basin is marked by chemical sediments including cherts, manganese and carbon-rich sediments.

\subsection{Structural Setting}

Regional scale deformation characterises mineralised zones within the Birimian Gold belts of Ghana. This is dominated by folding and thrusting focusing at the boundary of the volcanic and sedimentary basins. Shear zones are nearly parallel to bedding and schistosity where developed within the formation, lies in the axial plane direction. Zones of shearing and faulting are locally present in all the rocks, but are especially pronounced in the soft metasedimentary rocks. Within the shear zones the carbon bearing phyllites are converted into lustrous black graphitic schist, which are often crinkled or drag folded (Luebe et al, 1990). Isoclinal folding with nearly vertical axis occurs, but detailed fold structure of the Lower Birimian is difficult to unravel as marker horizons are lacking and major folds are rarely seen.

Post-mineralised faulting is observed locally at many places. Fault channels are rarely more than 5 $\mathrm{cm}$ wide, usually filled with black graphite gouge composed of brecciated phyllite and schist. Small faults containing graphitic-guoge which trend between east and southeast are occasionally seen in the mines (Kesse, 1985). Minor structures such as tension gash, quartz veinlet and jointing abound near the veins.

\section{Stability of Pits}

\subsection{Factors Influencing Rock Slope Stability}

Slope instabilities are usually precipitated by a 
variation in conditions such as changes in groundwater seepage/drainage, geological discontinuities, blast vibration or seismic shock that results in ground particle acceleration. Such changes may occur immediately after excavation, develop slowly over a number of years or may be imposed suddenly at any time (Whitlow,1995).

The effect of acceleration on ground particles often induced locally through blasting or seismic shock can significantly alter the network of forces which act on the sliding block system. The stability of the jointed blocks is influenced principally by gravitational stresses. Usually, the competence of the block weight acting parallel to sliding plane acts to promote failure.

Where horizontal-directed acceleration pulses may be induced, the block will have a measure of horizontal weight impart which will shift the net weight vector component from the sorely vertical direction. Should vertically-directed acceleration pulses be induced, they will only act to add to or counteract the gravity weight component. It is therefore not uncommon to observe failure along a newly created slip surface or along a pre-existing one (Nordlund and Radberg, 1995).

\subsection{Modes of Failure Mechanism Affecting Open Pit}

Quite a number of movements take place as a re- sult of shear failure along an internal surface or weak plane owing to general decrease in effective stress. They are classified according to Whitlow (1995) as:

Plane failure: This failure occurs when discontinuity striking approximately parallel to the slope face and dipping at lower angle daylight into the slope face, enabling the material above the discontinuity to slide.

Wedge failure: when two discontinuities intersect in such a way that the wedge of material formed above the discontinuity could slide out in a direction parallel to the line of intersection of the two discontinuities.

Toppling failure: this failure involves rotation of columns or blocks of rock about a fixed base. It may involve linear movement of rock blocks along bedding planes or near to sloping surface.

Rotational slips: this occurs characteristically in homogeneous soft rocks or cohesive soils; the movement taking place along a curved shear surface in such a way that the slipping mass slumps down near the top of the slope and bulges up near the toe.

\subsection{Geotechnical Pitwall Mapping}

Pitwall mapping was carried out to determine the dip amount, dip direction and type of discontinuities that were present at the Main Pit (MP) and the

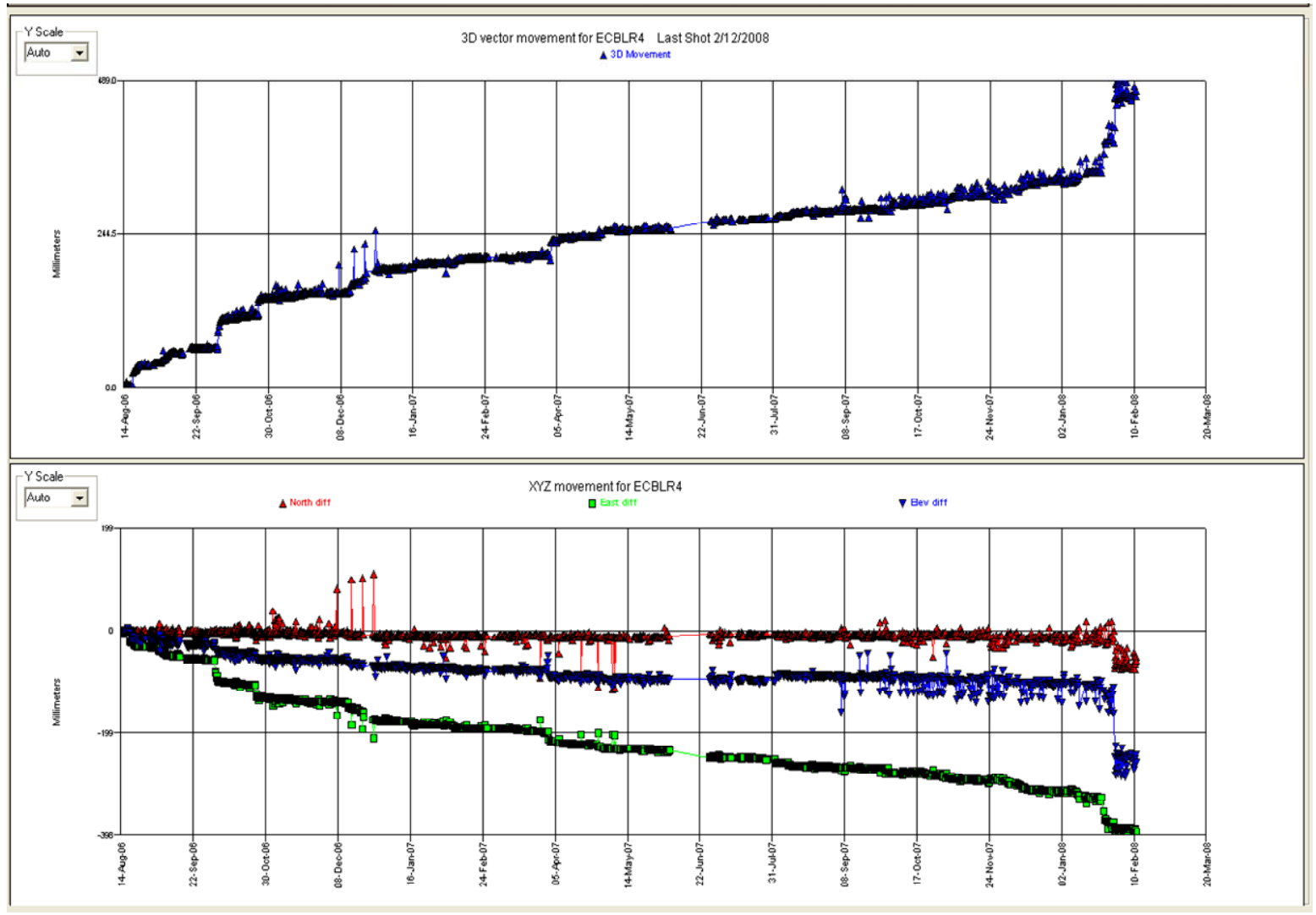

Fig. 3 Graph showing Relative Movement against Displacement Time 


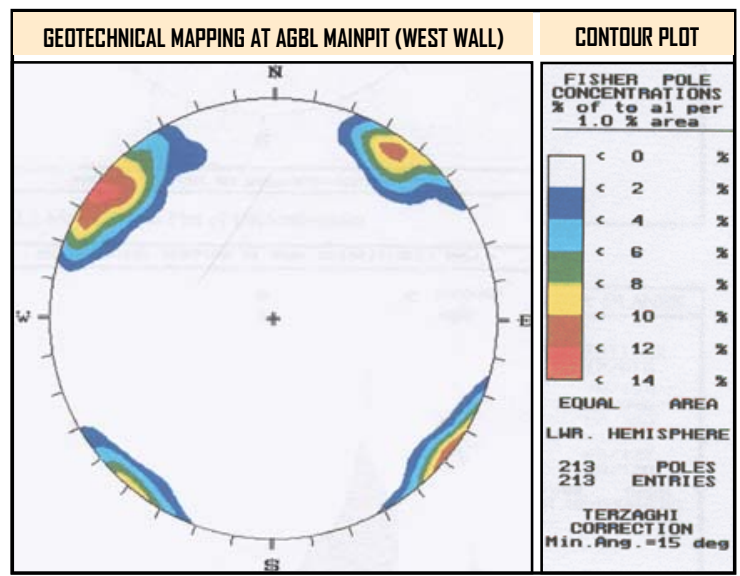

Fig. 4: Weighted Contour Plot of the Main Pit (MP) Discontinuities at the Central African Gold Ltd., Bibiani.

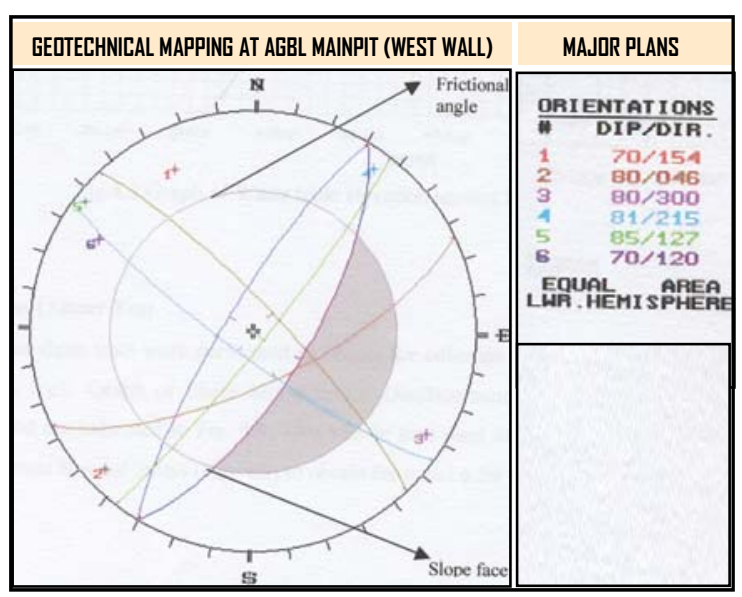

Fig. 5: Stereographic Plot of Discontinuities, Pit Slope and Friction Angle in MP

Plant North Pit (PNP). The discontinuities included joints, fractures and faults. All dip directions were taken with respect to the true north. The mapping was done on both the hanging and footwall. The values were then used to plot the stereonet and predict the slope stability behaviour using the Romana Slope Mass Rating (SMR). The potential mode of failure of the slope was deduced from stereographic analysis using measurement of dip and dip direction of the geological structures encountered on the pit walls loaded into the DIPS software. The variation of the attitude of the structures was eminent. The mapping revealed a significant change in orientation of geological structures necessitating a design modification.

\subsection{Observation of Pitwall Movement}

To ensure reliable monitoring of pitwalls stability, systematic surveys of the movements of regions within the walls were organised. About 77 prisms were installed along the berm and slope faces. The readings were picked at regular time intervals for the purpose of monitoring vertical and lateral movement (Fig. 3). The imperceptible slow movement down the slope was dependent on water saturation, stress loading and weak rock material. The plastic strain response depicted secondary creep, reflecting time dependent elastic deformation when stress loading was assumed largely constant.

At a point tertiary creep set in, indicating stress/ strain condition in which accelerated sample strain developed. The overall readings from movement verse time curve indicated that rate of movement could near $250 \mathrm{~mm}$ /day down the slope face, and with no change in applied stress, it was capable of triggering eminent creep failure.

\subsection{Stereographic Plot of Discontinuities}

The footwalls and hangingwalls of both the MP and PNP were plotted stereographically using the DIPS software. The weighted plot of the discontinuities is as shown in (Fig.4). The major planes of failure were identified as $70^{\circ} / 154^{\circ}, 80^{\circ} / 046^{\circ}$, $80^{\circ} / 300^{\circ}, 81^{\circ} / 215^{\circ}, 85^{\circ} / 127^{\circ}$ and $70^{\circ} / 120^{\circ}$ (Fig.5). Kinematic slope analysis carried out with the DIPS software indicated that potential for localised planar and toppling failure existed along the footwall.

\subsection{Slope Configuration}

The slope configuration measured along one of the deepest sections of the pit is as shown in Table 1 . As can be seen, the average batter and berm are $\mathrm{X}$ and $\mathrm{Y}$ respectively. However, the pits were expected to be mined using $65^{\circ}$ batter, $3 \mathrm{~m}$ berms and $12 \mathrm{~m}$ bench height.

Table 1 A Typical Slope Configuration

\begin{tabular}{|c|c|c|c|c|c|c|}
\hline $\begin{array}{c}\text { Overall } \\
\text { Angle }\left(^{\circ}\right)\end{array}$ & $\begin{array}{c}\text { Batter } \\
\text { Angle }\left(^{(}\right)\end{array}$ & $\begin{array}{c}\text { Berm } \\
\text { Width }(\mathrm{m})\end{array}$ & $\begin{array}{c}\text { Bench } \\
\text { Height }(\mathrm{m})\end{array}$ & $\begin{array}{c}\text { Inter } \\
\text { Ramp } \\
\text { Angle }\left(^{\circ}\right)\end{array}$ & $\begin{array}{c}\text { Maximum } \\
\text { slope } \\
\text { Height( } \mathrm{m})\end{array}$ & $\begin{array}{c}\text { Material } \\
\text { Type }\end{array}$ \\
\hline 38 & 50 & 6.5 & 12 & 35.8 & 60 & Oxide/Transition \\
45 & 55 & 4.5 & 12 & 42.9 & 60 & Oxide/Transition \\
50 & 60 & 4 & 12 & 47.8 & 60 & Oxide/Transition \\
50 & 60 & 3.5 & 12 & 48.8 & 100 & Fresh \\
55 & 65 & 3.2 & 12 & 53.8 & 100 & Fresh \\
\hline
\end{tabular}

\subsection{Slope Mass Rating (SMR)}

The Slope Mass Rating (SMR) is an empirical slope stability analytical method that was introduced by Romana (1985, 1993), as a logical follow up to the Bieniawski Rock Mass Rating (RMR) or geomechanical classification. RMR widely used in underground mining, is not the best classification system for slopes due to the fact that the stability of most slopes is structurally controlled. In the RMR system, thorough emphasis of the orientation of geological structures appears lacking.

SMR introduces four adjustment factors to the RMR to make up for these deficiencies. The adjustment factors added depends upon joint-slope relationships and a factor depending on methods of excavation. The SMR is computed using the rela- 
$S M R=R M R+\left(F_{1} x F_{2} x F_{3}\right)+F_{4}$ tionship be-

(Romana, 1985):

where:

$F_{1}$ depends on the angle between the strikes of the joints and the slope face. Its value ranges from

0.15 to 1.0 . This range was established but afterward was found to match the relationship $F_{1}=(1-$ $\sin A$ ) where $A$ is the angle between the strike of the slope face and the joint.

$F_{2}$ refers to the joint dip angle in the planar mode of failure. Its value ranges from 0.15 (for joints dipping less than $20^{\circ}$ ) to 1.0 (for joints dipping more than $45^{\circ}$ ). For toppling mode of failure, $F_{2}$ remains 1.0.

$\mathrm{F}_{3}$ reflects the relationship between slope face and joint dips. In the planar mode of failure, $F_{3}$ again refers to the probability that the joints 'daylight' into the slope face. For the toppling mode of failure, due to it nature, unfavourable condition cannot happen.

The adjustment factor for the method of excavation $\mathrm{F}_{4}$ has been fixed empirically. No special factors have been fixed for the wedge failure. The classification is applied for each of the joint systems. The SMR has a total range of $0-100$. The adjustment rating for joint is the product of the three factors $F_{1}, F_{2}$ and $F_{3}$

\section{Results and Discussions}

\subsection{Result of SMR Determination}

The SMR calculation is based on the criteria discussed in Section 3.7. The SMR of the hangingwall and footwall for the oxide/transition zones were determined. The calculation as outlined below in Table 2 was carried out using stability rat-

$$
\Rightarrow S M R=44+(0.15 * 1.0 *-6)+0=43.1
$$

ing from Romana's assessment chart (after Roman, 1993). The overall rating for some selected slopes within the Pits is as shown in Table 3.

Method of excavation: Mechanical (F4) $=0$

Stability assessment at angle $50^{\circ}$ is partially stable (Fig.4).

\subsection{Measures for Pitwall Failure Prevention}

Pitwall movement just like other mass movements, could be imperceptibly slow. Being a natural phenomenon, it is increasingly difficult to stop it once it has started. Preventive measures must therefore take the lead in control as later remedial action has often proved to be ineffective. Among the preventive measures are:
Table 2 Results from SMR Calculations

\begin{tabular}{|c|c|c|c|c|c|c|c|}
\hline \multicolumn{3}{|c|}{ Parameter } & \multicolumn{2}{|r|}{ Value } & \multicolumn{3}{|c|}{ Rating } \\
\hline \multirow{2}{*}{\multicolumn{3}{|c|}{$\begin{array}{c}\text { Intact rock strength } \\
\text { RQD }\end{array}$}} & \multicolumn{2}{|c|}{$11.8 \mathrm{Mpa}$} & \multicolumn{3}{|c|}{2} \\
\hline & & & \multicolumn{2}{|r|}{$75 \%$} & \multicolumn{3}{|c|}{17} \\
\hline \multicolumn{3}{|c|}{ Joint spacing } & & $105 \mathrm{~mm}$ & \multicolumn{3}{|c|}{8} \\
\hline \multicolumn{3}{|c|}{ Joint condition } & & mm cont. & \multirow{2}{*}{\multicolumn{3}{|c|}{10}} \\
\hline \multicolumn{3}{|c|}{ Groundwater } & & Wet & & & \\
\hline \multicolumn{3}{|c|}{ RMR } & & & \multicolumn{3}{|c|}{44} \\
\hline $\begin{array}{l}\text { Joint Dip } \\
\text { Direction, ? }\end{array}$ & $\begin{array}{c}\text { Joint Dip } \\
?\end{array}$ & & & \begin{tabular}{|l} 
Slope Face \\
Dip \\
$? ?_{\mathrm{s}}$
\end{tabular} & $F_{1}$ & $\mathrm{~F}_{2}$ & $\mathrm{~F}_{3}$ \\
\hline $345^{\circ}$ & $60^{\circ}$ & $302^{\circ}$ & & $50^{\circ}$ & & 1.00 & -6 \\
\hline
\end{tabular}

- High quality and timely drainage, including deep drainage (i.e., boreholes) of the rock making up the slopes, drainage of the surface in the vicinity of the mine and surface of the mine walls.

- Critical study of geologic and hydrologic conditions of the pitwall face, nature and types of discontinuities with the view of sealing off active ones, through timely cutbacks.

- Avoidance of overloading unstable pitwall surfaces and maintenance of dry mine wall faces

- Precise execution of designed plan, particu-

Table 3 Typical SMR for Selected Slopes

\begin{tabular}{|c|c|c|c|c|}
\hline Prospect & Designation & RMR & SMR & $\begin{array}{c}\text { Stability } \\
\text { Assessment }\end{array}$ \\
\hline \multirow{4}{*}{$\begin{array}{l}\text { Plant } \\
\text { North Main Pit }\end{array}$} & Footwall O/T zone & 44.0 & 43.1 & Partially stable @ $50^{\circ}$ \\
\hline & Footwall F/R zone & 60.3 & 64.0 & Stable @55 \\
\hline & Hangingwall $\mathrm{O} / \mathrm{T}$ zone & 44.0 & 44.0 & Partially stable @ $50^{\circ}$ \\
\hline & Hangingwall F/R zone & 61.0 & 61.0 & Stable @ $05^{\circ}$ \\
\hline \multirow{4}{*}{ North Shaft Pit } & Footwall O/T zone & 44 & 44 & Partially stable @ $050^{\circ}$ \\
\hline & Footwall F/R zone & 64 & 58 & Stable @ $55^{\circ}$ \\
\hline & Hangingwall $\mathrm{O} / \mathrm{T}$ zone & 44 & 39.8 & Partially stable @ $45^{\circ}$ \\
\hline & Hangingwall F/R zone & 61 & 43.5 & Partially stable @ $50^{\circ}$ \\
\hline
\end{tabular}

larly in terms of projected slope angles, bench geometries, etc.

\subsection{Discussions}

The potential modes of failure of the pitwalls were deduced from the stereographic analysis using measurements of dip and dip directions of the geological structures encountered in the pit. The variation of the attitude of beds with depth was quite common. This was buttressed with sensitivity analysis of the pitwall stability to the method of excavation employing the Romana's Slope Mass Rating. This approach was highly relevant because it highlighted the impacts of geological discontinuities which dominate failure in pitwall. 
The analysis indicated that within the pits, the stability of most of the walls were partially stable at an average overall angle of $50^{\circ}$, triggering possible planar or toppling failure. The assessment revealed that stability could be improved by means of pit dewatering and meticulous smooth wall blasting. Localised planar or toppling failure was a threat, as sustained wet condition in the pit slopes reduced effective stress. Induced penetrative tension cracks then empowered destabilising force. It is imperative therefore that the pitwall face be maintained at dump-to-dry state.

The observed value for the creep movement nearing $250 \mathrm{~mm} /$ day along the Main Pit (MP) pitwall was quite alarming. Careful study of geologic and hydrologic conditions, as well as structural characteristics suggested a need for an immediate creep arrest since it is easier to prevent the creep movement than to control it once it has started.

\section{Conclusions}

Induced pitwall failure mode, especially within the Birimian is more of composite failure (i.e., planar and/or toppling) and it is critical in oxide/ transition zones. Romana's Slope Mass Rating (SMR) is effective in early theoretical assessment of the pitwall stability. Relative movements nearing 250 $\mathrm{mm}$ /day threatens stability of pitwalls and damp-to -dry state pitwall face could be achieved through effective pit dewatering. Deep drainage, seal-off of active discontinuities and timely cutbacks are among the most effective measures in creep prevention that threatens pitwall failure. Indeed, preventive measures must take the lead in stabilising pitwall as later remedial action has often proved to be ineffective.

\section{Acknowledgments}

The author acknowledges the contribution made by all those who in different ways provided inputs in the acquisition of data for this paper. Special mention is made of Isaac Korankye-Boateng a former student of University of Mines and Technology, Tarkwa.

\section{References}

Kesse, G.O., (1985), The Mineral and Rock Resources of Ghana. A A Balkema, Rotterdam Netherlands, pp. 13-17.

Leube, A., Hirdes, W., Mauer, R and Kese G.O., (1990), The Early Proterozoic Birimian Supergroup of Ghana and some Aspects of its Associated Gold Mineralization Precambrian Res.,46, pp. 139-165.
Nordlund, E. and Radberg G., (1995), Bergmekanik. Kurskompendium, Tekniska Hogskolani, Lulea (Sweden), 191pp.

Romana, M., (1985), New Adjustment Ratings for Application of Bieniawski Classification to slopes. Int. Symposium on the role of Rock Mechanics (ISRM), Zacatecas, pp. 49-53.

Romana, M., (1993), A Geomechemical Classification for Slope: Slope Mass Rating. Pegmon. Vol.3, pp. 575-600.

Rose-Brown, D. M., (1972), Design Considerations for Excavated Mine Slope in HardRock. Research report No. 21, Department of Civ il Engineering, Geology, Miningand Mineral Technology. London Imperial col lege and Technology, 21pp.

Taylor, P.N., Moorbath, S., Leube, A. and Hirdes W., (1988), Geochronology and Crustal Evolution of Early Proterozoic Granite-greenstone Terrains in Ghana/West Africa (Abstr.) International Special Conference on Geology of Ghana with special Emphsis on Gold, Comm., $75^{\text {th }}$ Anniversary of Ghana Geological Survey Department, Accra, pp. 43-45.

Whitlow, R., (1995), Basic Soil Mechanics. $3^{\text {rd }}$ Edition. Longman, Malaysia, pp. 346-347.

\section{Authors}

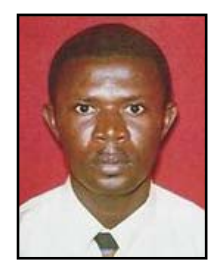

M. Affam is a lecturer in Geotechnical Engineering at University of Mines and Technology, Tarkwa, Ghana. He holds an MSc degree in Mineral Exploration and BSc in Geological Engineering from Kwame Nkrumah University of Science and Technology, Kumasi. He is currently a $\mathrm{PhD}$ student researching in rockburst potential in Ashanti deep mine. He has since graduation worked for a number of mining and exploration companies in Ghana. He is a member of a team of experts that provide geotechnical consultancy services to mining and allied companies. He is a member of GhIE, GhIG and CIM/ICM.

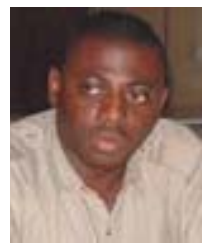

K. J. Allen is a graduate from University of Mines and Technology, Tarkwa. He holds MSc degree in Geological Engineering and Diploma in Geomatic Engineering. He has vast experience in mining covering several years and currently works as Mining Superintendent at Golden Star Resources, Bogoso/ 